\title{
SOME INITIAL EXPERIMENTAL RESULTS ON THE CONDITIONS OF FREE WATER LAYER FORMATION IN HORIZONTAL PIPES
}

\author{
Nguyen Duy Thien, Nguyen Van Diep, \\ DUONG NGOC HAI, NGUYEN HONG PHAN \\ Institute of Mechanics, NCST of Vietnam
}

\begin{abstract}
This paper presents an experimental facility conducted in Hanoi Institute of Mechanics to investigate multiphase flow pattern in the pipes. First and foremost, it is used to define the conditions of water layer formation in the horizontal pipe.

Experimental results have been obtained in stainless steel pipes of three different diameters $(24.6 \mathrm{~mm} ; 30.8 \mathrm{~mm}$ and $40.5 \mathrm{~mm})$ with white spindle oil $\mathrm{N}^{\circ} 10$ and water. They have been shown in the form of water layer maps.
\end{abstract}

\section{Introduction}

Note that the simultaneous flow of oil, water in the pipes is a practical importance. Water and oil are immiscible liquids, they have differences in characteristics, such as density, viscosity, surface tension and so on. Flow pattern, free water layers which usually contacted with the walls of the pipe influence not only on flow charaterestics (such as pressure drop, liquid hold-up correlations) but also life of the pipe (ex. influence on electro-chemical corrosions).

In order to get the proper design and operation of the producing and transporting oil facilities and to control their performance, it's very important to have knowledge of the flow characteristics of the multiphase flow, such as flow pattern, pressure drop, liquid holdup and so on, especially conditions that waters will be gathered into one place, and let the water layer appeare.

The determination of conditions of existence and transition from one of flow pattern to another is very complicated. There are numerous of experimental studies on this problem. Guzhov A. I., Grishin A. D.,...(1973) [1], conducted experiments in which the ratio of viscosities of oil/water is 20.4 and the ratio of denties of oil/water is 0.897 . The flow was investigated in pipes with inner diameter of $39.4 \mathrm{~mm}$. They for the first time have proposed a flow map. Some other interesting results have been obtained by G. F. Hewitt and his collaborators (1995) in 
their study of flow pattern, pressure gradients and prediction of oil-water flows in the horizontal tubes [4]. Together with P. A. Angeli (1995) [5], they used facility TOWER (Two phase oil-water Experimental Rig) to measure interface positions of stratified flow and drop sizes of dispersed flow and their distribution.

One experimental model developed by Medvedev V. F., Guzhov A. I., Boiko V. I. (1984) and Boiko V. I., N. T. Khang (1997) gives the results in close-set match with experimental ones [6].

It's too large and too difficult to consider all over problems. In this paper, we consider only one: the formation of free water layer in the pipe.

\section{Experimental Facility}

The following facility shown in Fig. 1 has been used to discover how and when water layer appears on the bottom of the pipe.

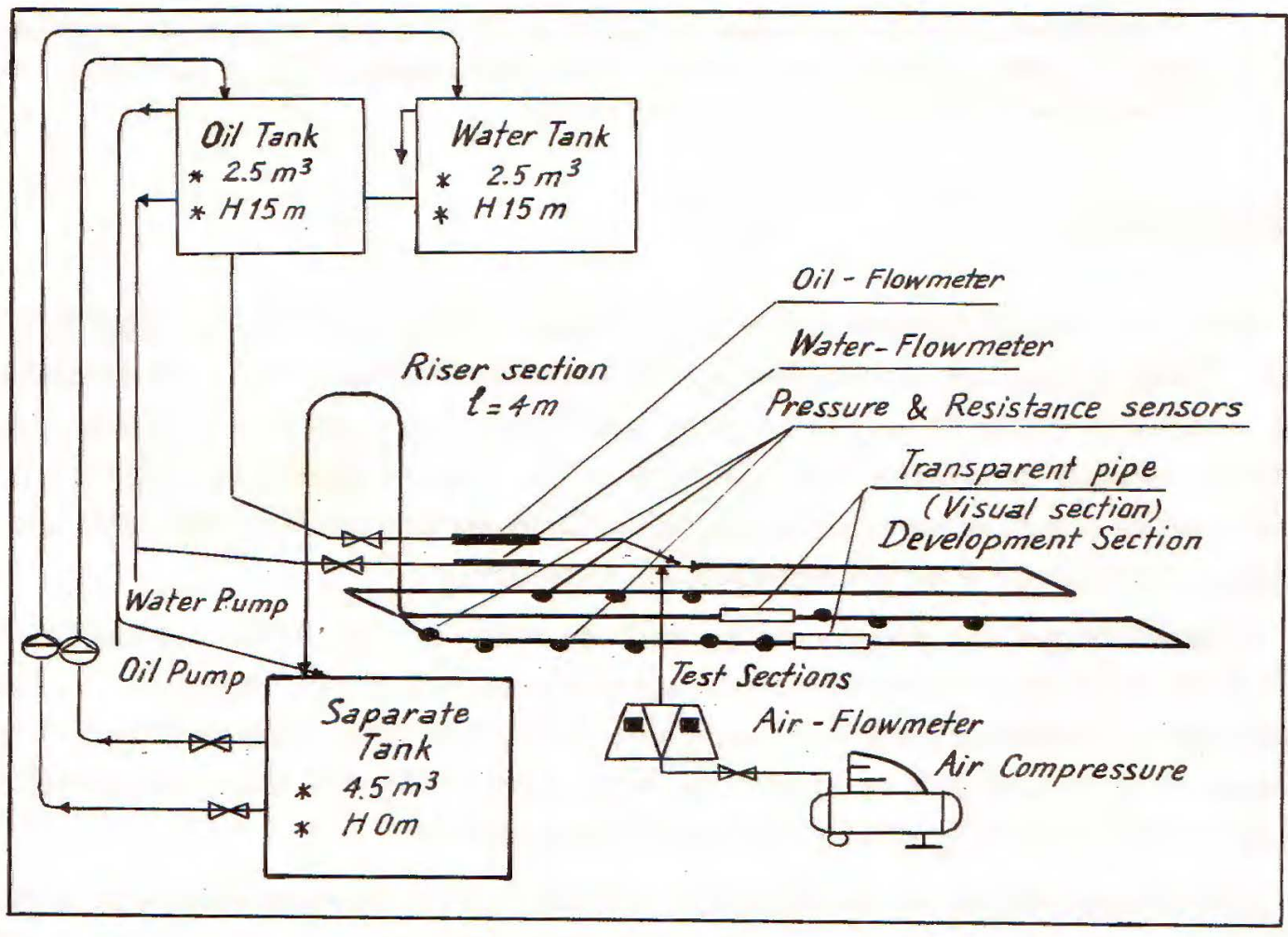

Fig. 1. Schematic diagram of IOM experimentalfacility

The test sections manufactured from round stainless steel tubes; the inner diameters of which are $24.6,30.8 \mathrm{~mm}$ or $40.5 \mathrm{~mm}$; the length of tube is $7 \mathrm{~m}$ per one (each tube has two parts: development section and test section, which have 
the same inner diameter). The water and oil are transported separately from the tanks of $14 \mathrm{~m}$ high from the plane where the pipes are located. They are mixed, then full developed in the developing sections with $3.5 \mathrm{~m}$ lengh.

Mean velocities of each phase are measured by Ultrasonic Flowmeters for fluid PT 868 (USA) before mixture and can be varied or kept constant by regulator valves. Water explorer, pressure transducers, thermocouples and transparent pipe were installed to study the flow dynamics, especially to discover the water layer which contact with the pipe walls.

\section{Exploring technique}

The main technique for discovering free water layer on the bottom of the pipe is an electro-resistance measuring one. Note that spindle oil is non-conductive material in comparison with water, resistance of mass flows across the place where the water sensor was installed reflects what is being.

The main components of the water sensor and it's activity principle are shown in the Fig. 2.

In the Fig. 3 we can see the normal signals of water sensor: in the first part of this figure there is a thick water layer contacted with the walls of the pipe; in the second, water layer doesn't contact with the walls; and in the last: intermediate case.

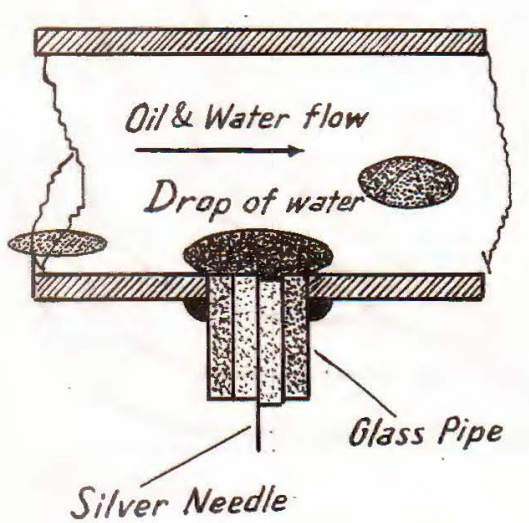

Fig. 2. Construction of water-recognize-sensor

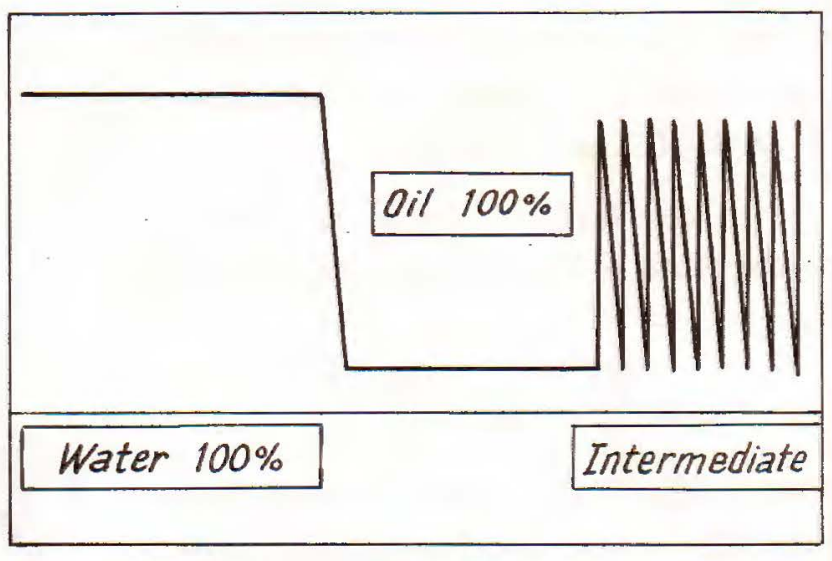

Fig. 9. Normal signal of water sensor

\section{Experimental results}

Results of water layer measurements for oil-water two-phase flow in the hori- 
zontal pipe are presented in the Fig. 4,5 and 6.

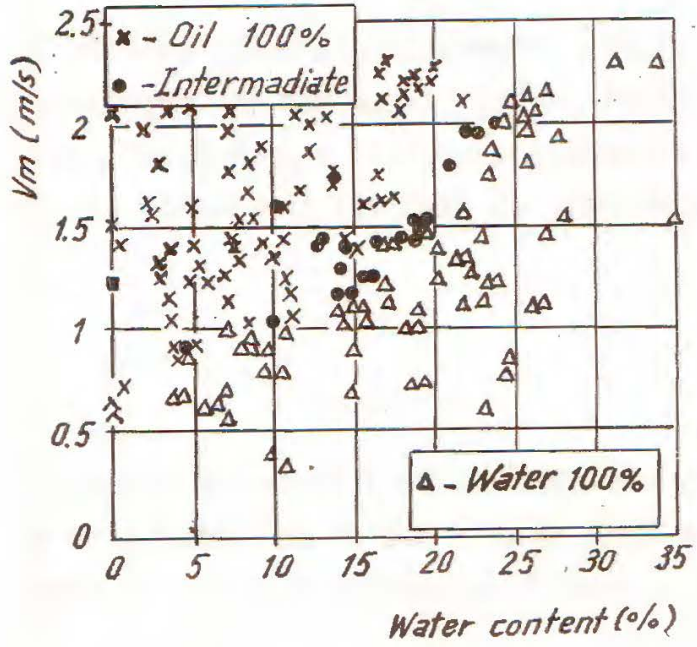

Fig. 4. Water layer map of the wateroil flow in the tube ID $=26.6 \mathrm{~mm}$

Fig. 4 submits experimental results obtained on stainless steel pipe which inner diameter (ID) is 24.6 mm; Fig. 5 corresponds to the pipe which ID is $30.8 \mathrm{~mm}$. The last figure is used to present the boundaries of states of the flow in the pipes with inner diameters of $24.6,30.8$ and $40.5 \mathrm{~mm}$.

In the figures, the mean velocity of the flow is $V_{m}$ and water content is $\beta$ :

$$
V_{m}=\frac{Q_{\ell}}{S}, \quad \beta=\frac{Q_{w}}{Q_{\ell}}
$$

where: $Q_{\ell}=Q_{0}+Q_{w} ; S$-area of the tube; $Q_{w}$-water flow and $Q_{o}$-oil flow.

The figures show that the conditions of free water layer formation in horizontal pipes depend not only on the flow velocity, water content but also on inner diameter of the pipe.

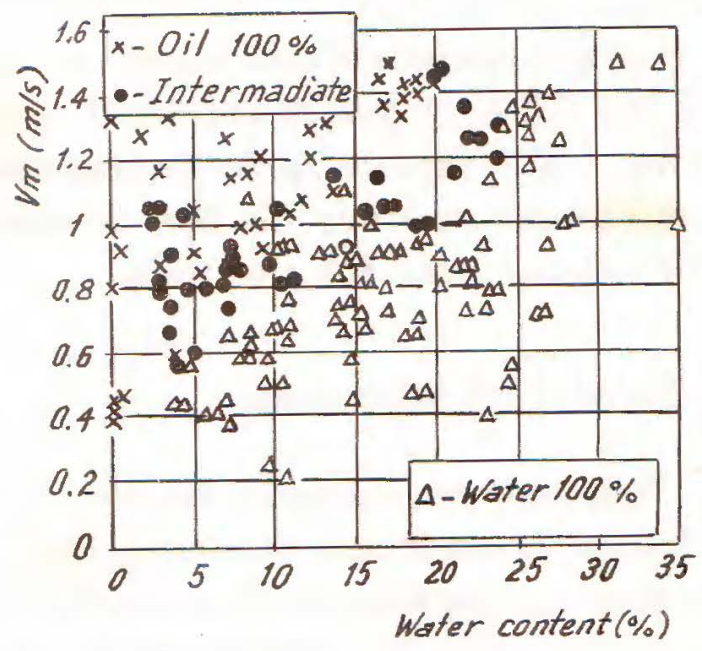

Fig. 5. Water layer map of the wateroil flow in the tube ID $=30.8 \mathrm{~mm}$

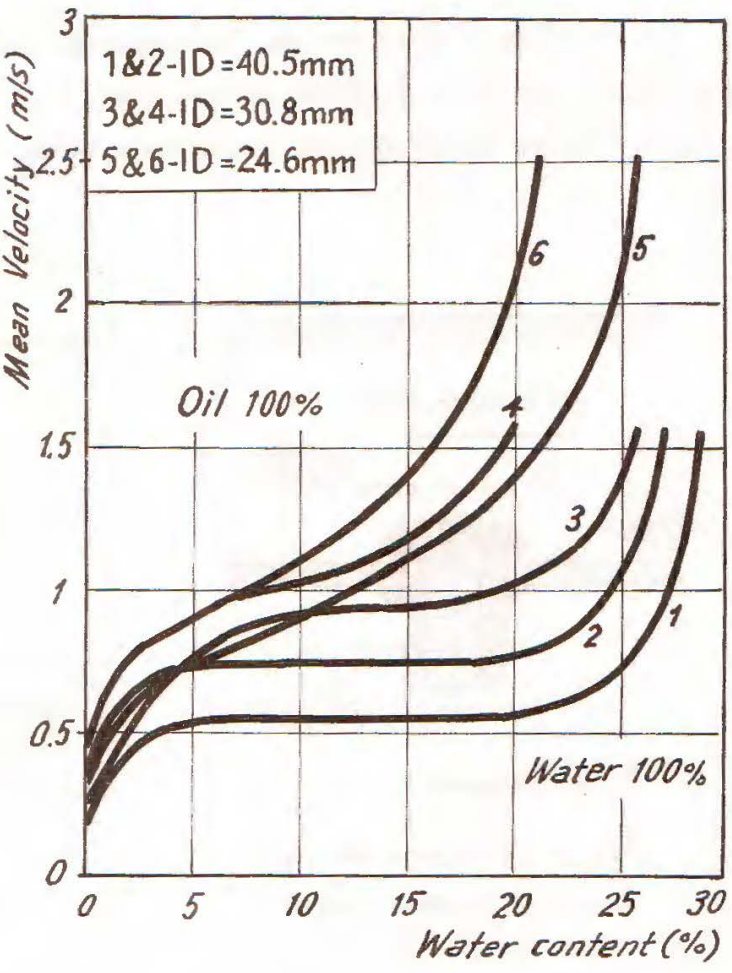

Fig. 6. Water Layer Map of the wateroil layer $(\mathrm{ID}=24.6,30.8 \& 40.5 \mathrm{~mm})$ 
We can remark on the each flow structure that: generally, the stractified flow exists when the flow rate of mixture is not high (about $0.5 \mathrm{~m} / \mathrm{s}$ ), water is always deposited, there is formation of water layer on the bottom of the pipe. It is still exists when flow velocity increases till to a certain value.

The experimental results show that the prediction the formation of water bed in the pipe can be obtained by using the combinations of measurement of the oil, water velocities and the fluctuation of electro-resistance signal. These experimental results can be used for developing and verifying theoretical predicting models.

They also can be used for predicting and/or to regulating flow pattern of oil-water flow in the pipe. It will be the subject of our following investigation.

\section{Conclusion and acknowledgment}

This paper presents some initial results in constructing and using the experimental facilities to study the flow pattern two-phase oil-water pipe flow. Obviously, these facilities are needed in a future improvement.

The authors wish to thank J.V. Vietsovpetro, National Center for Natural Science and Technology of Vietnam and Vietnam Foundation for Basic Research in Natural Sciences for the financial support.

\section{REFERENCES}

1. Guzhov A. I., Grishin A. D., Medredev V. F., Medredeva O. P. Emulsion formation during the flow of two immiscrible liquids, Neft. Choz., (in Russian), Vol. 8, pp. 58-61, 1973.

2. Corteville R. Stehlé, D. Pauchon. An experimental study on severe slugging in Multiphase. J. 1995.

3. Fabre, L. L. Peresson, J. Corteuille, T. Boargeois, R. Odello. Severe Slugging in Pipe line/Riser System. J. SPE, 1997.

4. A. P. A. Kurban, M: A. Mendes-Tatsis, G. F. Hewitt. Oil-Water Flows in Horizontal Tubes the 1995 ICHEMI Research Event / First European Conference, 757-759, 1995.

5. A. P. A. Kurban, P. A. Angeli, MA Mendes-Tatsis, G. F. Hewitt. Stratified and dispersed oil-water flows in horizontal pipes., Multiphase 95, Cannes, 7-9 June 1995.

6. Boico V. I., N. T. Khang. The effect of oil-gas-water flow regime on corrosion 
of transport-pipe. Second International Conference on safety life of transportpipe, 28 august 1997.

Received June 7, 1999

\section{MỘT SO̊ KÊT QUA THỰC NGHIỆM BAN ĐẦU VỀ CÁC ĐIỀU KIỆN HìNH THÀNH LỚP NƯớC TƯ DO TRONG ĐƯờNG ỐNG NÅM NGANG}

Bài báo trình bày một thiết bị thí nghiệm của Viện Cơ học, được thiết kế để nghiên cứu dòng nhiều pha trong đường ống. Trước hết, nó được sứ dụng để xác định các điều kiện hình thành và tồn tại lớp nước sát đáy ống trong dòng chảy hai pha dầu-nước.

Kết quả thực nghiệm với dòng hai pha dầu White Spindle \#10 và nước, trong các ống có đường kính $24.6,30.8$ \& 40.5mm được trình bày trên bản đồ phân vùng cấu trúc dòng cháy. 